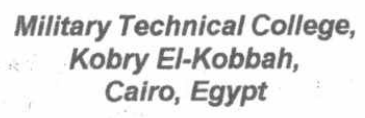

$9^{\text {th }}$ International Conference

On Aerospace Sciences \&

Aviation Technology

\title{
CONTROL OVER BLAST WAVE AT EXIT POINT OF SUPER-SONIC PROJECTILE
}

\author{
Abu-Elkhair* M. S., Sherif* H. A., Said* S. M.
}

\begin{abstract}
:
Sound field produced from explosion always attracts the scientists to deal with. Regarding to the traveling projectiles, sound field is interpreted due to two main parameters, the first parameter is owing to the effect of pressure wave and pressure difference behind the projectile at exit moment, while the second parameter is related to the sound produced by the velocity of the flying projectile.

In the present work; due to difficulty in controlling the component of sound generated from hypersonic flying objects, sound wave parameter have been excluded, while the effect of pressure wave is taken into consideration. The arrangement shown hereinafter has been tested thoroughly, and the results were recorded at different velocities and distances. Results have shown that this method of control has a great effect on reducing the sound produced due to firing, and the model has been verified as tested on the Automatic Rifle $7.62 \times 39 \mathrm{~mm}$. This work aims to verify experimentally the performance of the modified silencer.
\end{abstract}

\section{KEY WORDS}

Blast-Waves, Internal Ballistics, Weapons, Barrel Muzzle, Discharging of gases, Silencer, Sound wave and Pressure wave

\footnotetext{
* Egyptian Armed Forces.
} 


\section{1-INTRODUCTION :}

A current focus of the recent army ballistic research program involves the numerical calculation of compressible flow in silencer muzzle device, diffusing a portion of the flowing gases behind the projectile base after the projectile left the barrel. The basic idea of the silencer is to decay the energy of gases flowing out by passing it through multi-chambers of silencer. The silencer attenuates the sound generated due to sudden expansion of the powder gases discharging from muzzle. In the interest of economizing resources, for the field calculations it is desirable to employ simple twodimensional flow models. The construction of which will be presented hereinafter. The discharge of compressible flow through nozzles has a wide civilian applications and has been studied in a number of references in the field of gas dynamics. A few publications are devoted to the military applications, especially on muzzle devices [1-5]. There are two old models of the silencers, the first model has multi-chambers while the second one contains disc rubbers inserted in hollow cylinder. Both of them have been used with subsonic projectiles in pistols. In this work, a silencer was manufactured combining the construction of the above two types and was applied on the supersonic projectiles of automatic rifle $(7.62 \times 39 \mathrm{~mm})$. The model has been manufactured; tested and verified in field by real firing, and the results have been analyzed and presented as obtained from field tests.

\section{2-SILENCER CONSTRUCTIONAL ARRANGEMENT:}

The proposed model; as shown below in Fig. 1 consists of:

[-Multi stage conical diffusers

2-Front conical exit diffuser

3-High resistant rubber blocks

4-Displacement perforated block

5-Circumferential perforated casing

6-Front locking nut

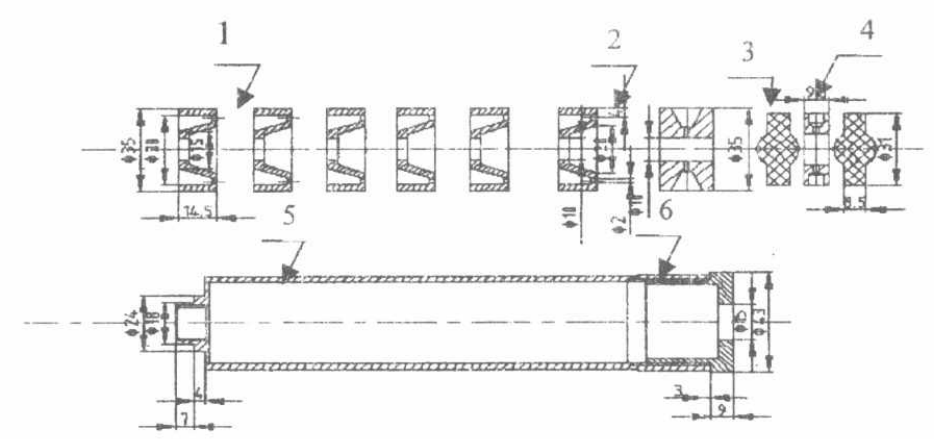

Fig.1-a.Envelope and constituents of the proposed silencer 


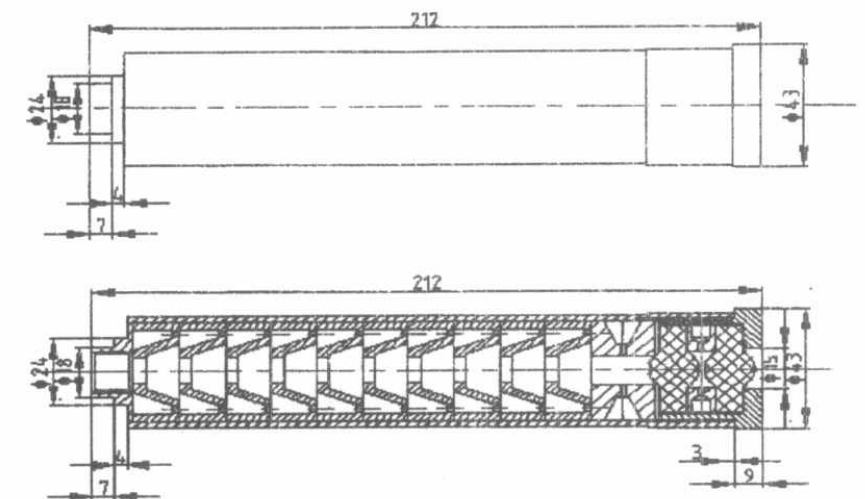

Fig.1-b. Longitudinal section in the assembled automatic weapons silencer

The early mentioned construction of the proposed silencer is adopted; it represents the extract of many other models reaching to this final arrangement. The system concept is based upon diffusing the main pressure flowing behind the projectile base before the exiting point. The concept of reduction stages represents the main scheme of the designed equipment where specially designed conical diffusers are used (see Fig.2.a).

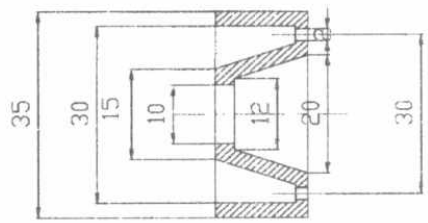

Fig.2.a Detail drawing of a diffuser cup

The diffused pressure of gases is planned to escape to the atmosphere through a set of two stage circumferential nozzles where the nozzles have circular cross-sections and conical exits, as shown in figure 2.b:

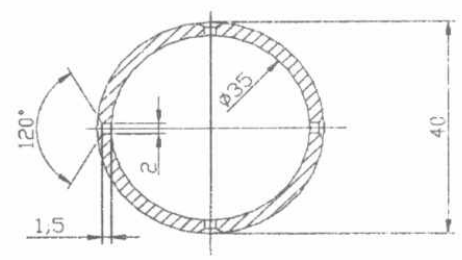

Fig 2.b Scheme of the circumferential exit openings 


\section{2-THEORETICAL BACKGROUND:}

The internal ballistic of the weapon could be evaluated by solving the set of the basic governing equations which are listed as follows:

2.1-Equation of motion of projectile [5]:-

$$
\begin{aligned}
& \mu \frac{d v}{d t}=P S \\
& \mu=i \cdot \frac{q}{g} \cdot\left(1+\frac{\lambda \omega}{q}\right)
\end{aligned}
$$

where:

$$
\begin{array}{ll}
\mathrm{P} & \text { pressure of powder gases [pa]. } \\
\mu & \text { equivalent (fictive) mass of projectile }[\mathrm{kg}] . \\
\mathrm{S} & \text { cross section area of firing barrel }\left[\mathrm{m}^{2}\right] . \\
\lambda & \text { constant coefficient. }(\lambda=0.25) \\
\mathrm{i} & \text { shape coefficient of projectile }(i \approx 1.1) \\
\mathrm{v} & \text { velocity of projectile }[\mathrm{m} / \mathrm{sec}] . \\
\omega & \text { weight of propellant charge }[\mathrm{kg}] . \\
\mathrm{q} & \text { weight of projectile }[\mathrm{kg}] .
\end{array}
$$

2.2-Energy equation (Resal's Equation):

$$
\frac{1}{2} \mu v^{2}=\frac{f \omega \psi}{k-1}-\frac{P C}{k-1}
$$

where:

$$
\begin{array}{ll}
\text { f } & \text { force of propellant charge }[\mathrm{Nm} / \mathrm{kg}] . \\
\omega & \text { mass of propellant charge }[\mathrm{kg}] . \\
\psi & \text { relative burnt amount of propellant. } \\
\mathrm{k} & \text { specific heat ratio }\left(\mathrm{k}=\frac{\mathrm{c}_{\mathrm{p}}}{\mathrm{c}_{\mathrm{v}}}\right) . . \\
\mathrm{C} & \text { free volume behind projectile }\left[\mathrm{m}^{3}\right] .
\end{array}
$$

2.3-Equation of burning of propelling charge:

$$
\frac{d \psi}{d t}=A \Phi(\psi) f(P)
$$

where:

$\Phi(\psi) \quad$ Geometrical form function of burning propellant.

2.4-Equation of state:

$$
P C=f \omega \psi T / T_{v}
$$

where:

T temperature of burned propellant at any time $\left[{ }^{\circ} \mathrm{k}\right]$

$\mathrm{T}_{\mathrm{v}} \quad$ explosion temperature $\left[{ }^{\circ} \mathrm{k}\right]$ 
These fundamental equations have attracted the interest of many researchers. Using ready made Computational Fluid Dynamics (CFD) programs makes it easy to plot the pressure contours behind the projectile base, but till now the experimental work has the dominancy. Beside which the solution of this set of characteristic equations reveals the variation of the history of the main ballistic parameters; pressure, velocity and displacements. Accurate knowledge about gas flow parameters at barrel muzzle is required, so that the software for internal ballistics was implemented for this purpose. At the instant of the projectile departure from the barrel muzzle equipped with silencer or without, assuming the gases adjacent projectile base having the magnitude and direction of projectile velocity.

It has been found that the study of such system requires inlet data at the muzzle point, i.e. inlet of silencer. The solution of the above set of equations gives the pressure history inside the barrel bore or as well as the velocity variations with time and displacement. Consequently, the parameters at the end of barrel are used as the parameters at the inlet of silencer while the outlet is achieved experimentally.
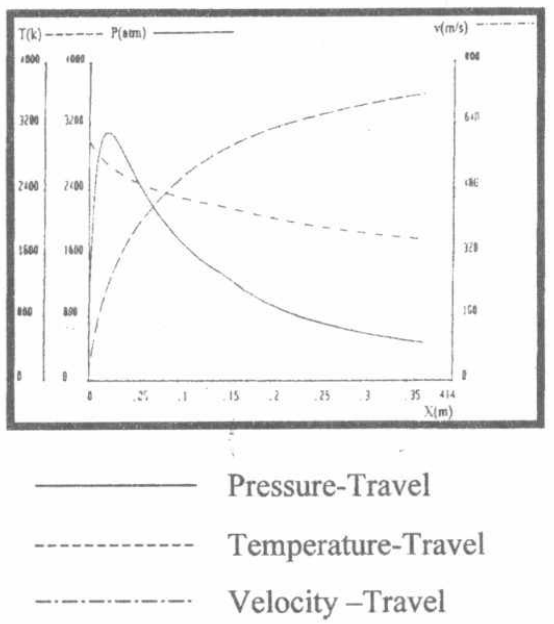

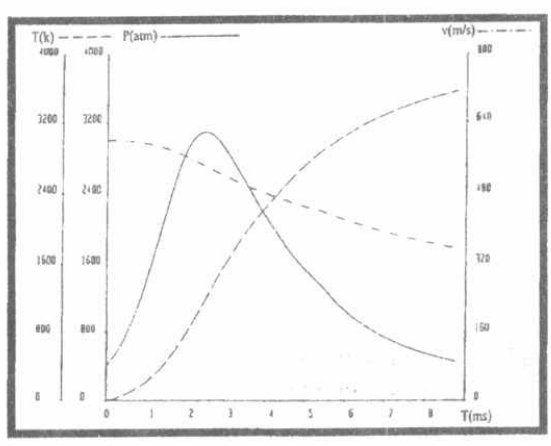

Pressure-Travel

Temperature-Travel

Velocity -Travel

Fig.2 Ballistic curves of the Automatic Rifle [caliber 7.62x39 mm AKM].

On other hand; it is well known that all automatic weapons are characterized by their supersonic projectile velocities. In this essence it is recommended to find out a formula to represent the relation between velocity of the projectile with respect to the velocity of flowing gas particles at the inlet of the silencer; as well as inside the silencer stages. This relation is presented here as a function of gases pressure and density with the Mach number (M), it has the form [6] :-

$$
M=(\rho . v / k P)^{1 / 2}
$$

where: $\rho$ density of gases $\left[\mathrm{kg} / \mathrm{m}^{3}\right]$. and the pressure $\mathrm{P}=\rho \mathrm{RT}$ 


\section{3 - SILENCER EFFICIENCY}

The assessment of silencer performance can be achieved through the measurement of sound pressure level due to firing of automatic rifle in free field, with and without silencer. The sound intensity is defined as [ 9 ]:
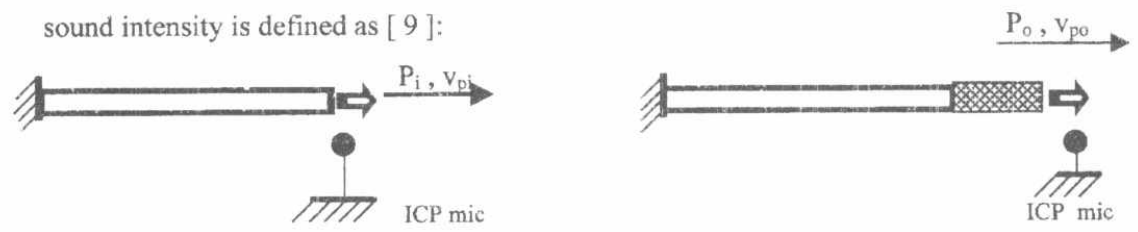

$\vec{I}=P \cdot \vec{V}$

(6)

$\mathrm{P} \quad$ is the complex sound pressure $[\mathrm{Pa}]$.

$\vec{V} \quad$ is the particle velocity $[\mathrm{m} / \mathrm{s}]$.

It can be shown that the silencer efficiency $\eta$ (or performance) can be obtained through the calculation of sound intensity attenuation due to use of silencer mounted on barrel muzzle:

$$
\eta=\frac{\left|\vec{I}_{1}\right|-\left|\vec{I}_{0}\right|}{\left|\vec{I}_{i}\right|}
$$

where:-

$$
\vec{I}_{i}=P_{i} \vec{V}_{i} \quad \text { and } \quad \vec{I}_{O}=P o \cdot \vec{V}_{O}
$$

A plane wave propagating in free field (which is the case in this work) is a pure active sound field. In this case; the particle velocity $V_{p}$ can be calculated using the following formula:

$$
\mathrm{V}_{\mathrm{p}}=\mathrm{P} / \rho_{\mathrm{p}} \cdot \mathrm{c}
$$

Where

$$
\begin{array}{ll}
\text { c } & \text { speed of sound in air. }(344 \mathrm{~m} / \mathrm{sec}) \\
\rho_{\mathrm{p}} & \text { air density. }
\end{array}
$$

The magnitude of the intensity is thus given by :

$$
|I|=\frac{P_{r m s}^{2}}{\rho_{p} \cdot c}
$$

where $P_{\mathrm{rms}}$ is the root mean square value of sound pressure ievel.

From equations (7), (8) and (10), the silencer efficiency is written as:

$$
\eta=1-\frac{P_{0}^{2}}{P_{i}^{2}}
$$

As a matier of fact, for constant cross sectional area of the silencer; the sound intensity will be a measure of the acoustic power ílow. 


\section{4 -EXPERIMENTAL WORK}

This work aims to verify experimentally the silencer efficiency or performance. The test rig includes the automatic rifle $(7.62 \times 39 \mathrm{~mm})$ with the modified silencer, blast and vibration monitoring analyzer for measuring sound pressure level of exploded charge at the outlet of weapon barrel or silencer gases, and chronograph type UVS (Nitro) for measuring projectile muzzle velocity. Figure 3.a shows a photograph of test rig and a scheme of instrumentations in the shooting range in fig. 4.

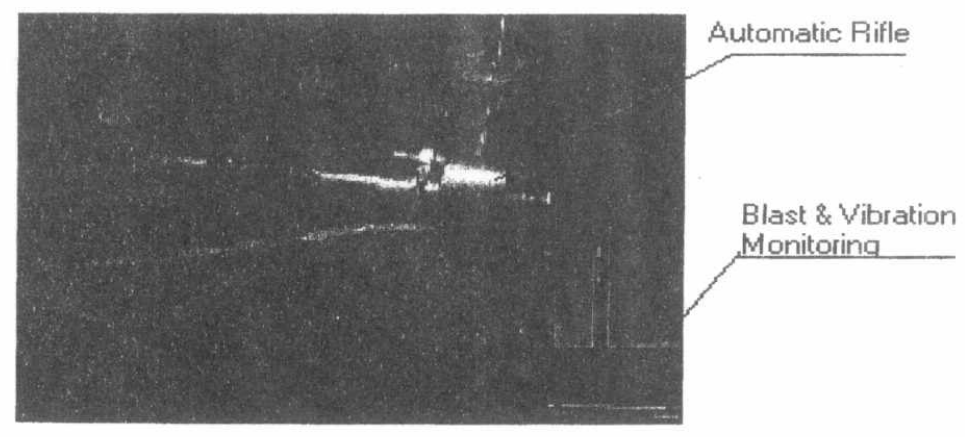

Fig. 3 Photograph of Automatic rifle $7.62 \times 39 \mathrm{~mm}$ AKM fixed on test rig without silencer .

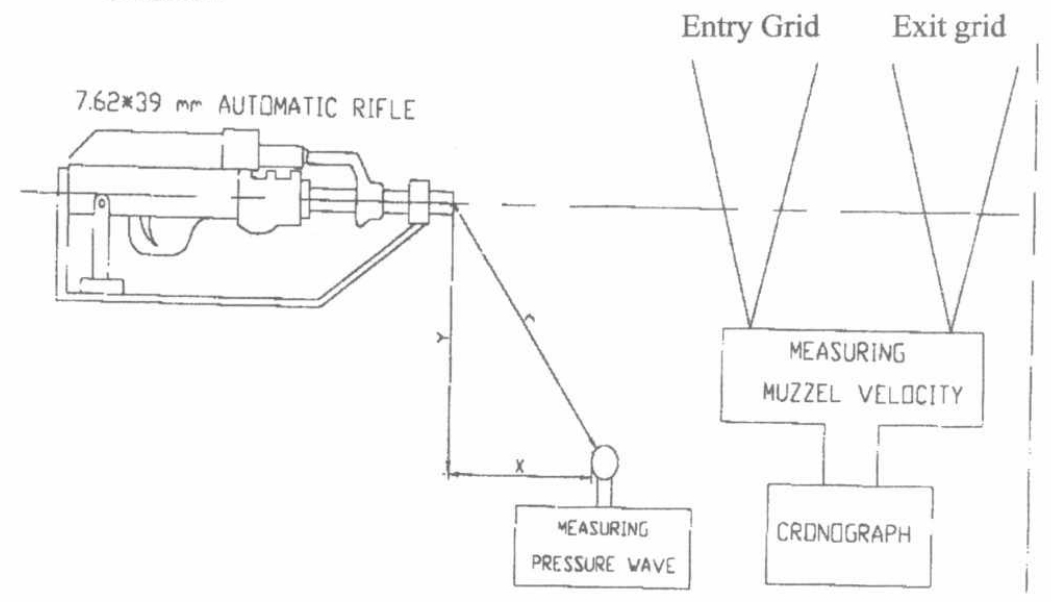

Fig. 4. Schematic drawing of the setup of automatic rifle $7.62 \times 39 \mathrm{~mm}$ AKM fixed on test rig for measuring sound pressure wave and projectile muzzle velocity. 
Figure 5 gives the block diagram of instrumentations used in measuring pressure and velocity:-

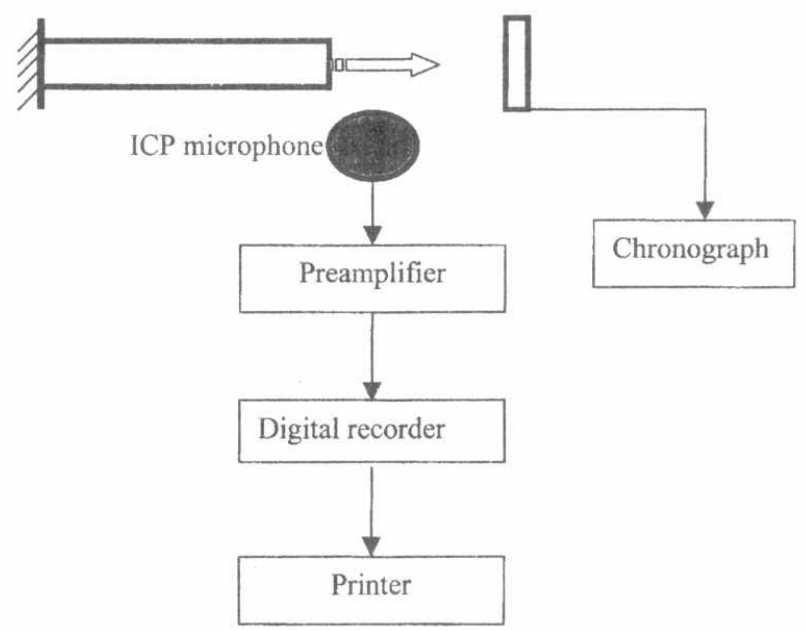

Fig. 5 Block diagram of the instrumentations used in measuring pressure and velocity

Group of tests were planned and carried out in the central laboratory of the ballistic indoor shooting range. The parameters affecting sound suppression are examined, while the records of sound pressure and forces are stored on a tape recorder for the analysis, all parameters affecting the phenomena are considered. Records are taken at different distances from the exit point, at the same time, different charges are used to obtain sonic and supersonic speed of the projectile through variation of the quantity and characteristics of the propellant charge. Table (1) explains the regime of tests:

Table (1): Regime of firing tests

\begin{tabular}{|c|c|c|c|}
\hline No. of shots & Loading Charge & $\begin{array}{c}\text { Muzzle Velocity } \\
{[\mathrm{m} / \mathrm{sec}]}\end{array}$ & $\begin{array}{c}\text { Recording } \\
\text { distance }[\mathrm{m}]\end{array}$ \\
\hline 5 & Complete charge & $\geq 700$ & 2 \\
5 & & & 10 \\
5 & & $\leq 340$ & 25 \\
\hline 5 & Reduced charge & & 11 \\
5 & & & 25 \\
5 & & & \\
\hline
\end{tabular}




\section{5 -ANALYSIS AND DISCUSSION OF TEST RESULTS:}

It has been shown in the present work that the use of silericers; especially the adopted arrangement will affect the firing arms in two direction. The main thoughts belongs to the main objectives of using silencer, where it is required to diminish or reduce the noise generated as a result of firing, while the indirect belongs to the accuracy of firing, in other formulation. The sound pressure level due to firing as well as the projectile muzzle velocity were measured for the rifle in both cases without and with silencer, also with full charge and reduced charges. Fig. 6 shows the recorded sound pressure level due to firing without silencer where the sound pressure detected was silencer $\left(\mathrm{P}_{\mathrm{rms}}\right)=362.5 \mathrm{~Pa}(145.2 \mathrm{~dB})$. The rms value of sound pressure depicted while using the silencer was $\left(\mathrm{P}_{\mathrm{rms}}\right)_{\mathrm{i}}=32.5 \mathrm{~Pa}(124.2 \mathrm{~dB})$ with the first shot as it is shown in fig. 7. For a second shot with the same silencer, the sound pressure level was reduced to $\left(\mathrm{P}_{\mathrm{rms}}\right)_{0}=29.25 \mathrm{~Pa}(123.3 \mathrm{~dB})$. However, it seems that the silencer has slightly lost its performance at the third shot since $\left(\mathrm{P}_{\mathrm{rms}}\right)_{0}$ attained a value of $41.5 \mathrm{~Pa}(126.34 \mathrm{~dB})$. This moderate change can be referred to the state of consumption of the rubber blocks mounted in the front part of the silencer.

Using equation (11), it can be shown that the silencer efficiency for the first shot reaches $99.2 \%$, and $99.3 \%$ for the second shot. For the third shot, the efficiency dropped to $98.7 \%$, which in all cases represent good achievement.

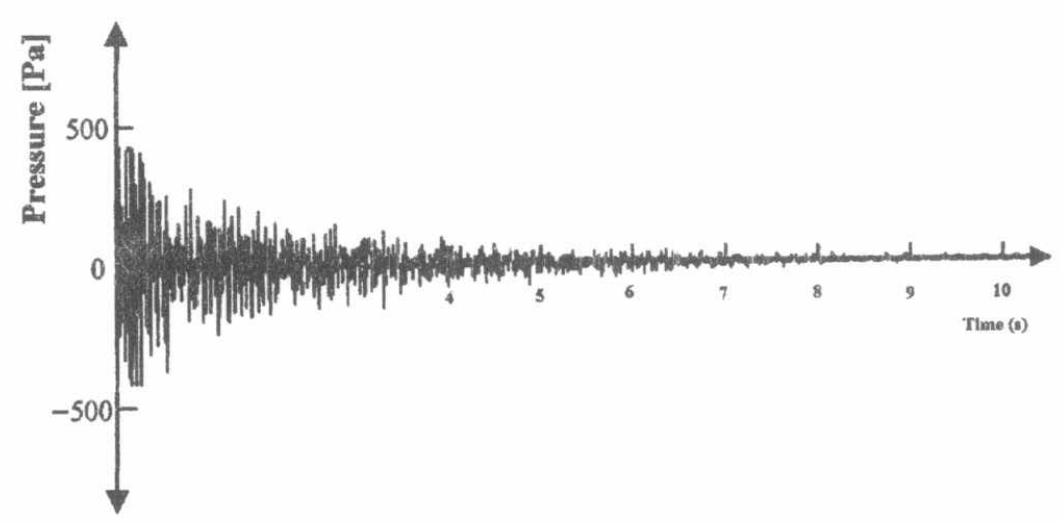

Fig. 6 Pressure wave at exit point without silencer $\left(\mathrm{P}_{\mathrm{mms}}\right)=362.5 \mathrm{~Pa}(145.2 \mathrm{~dB})$ 


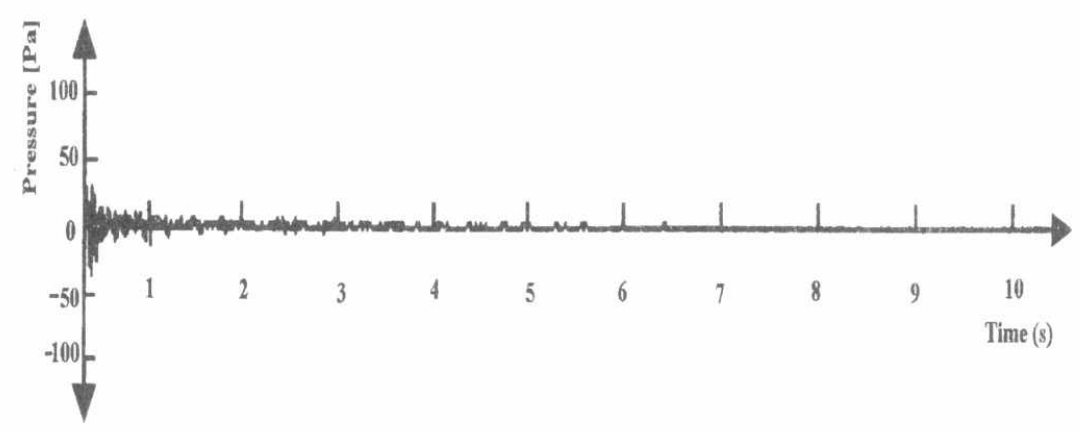

Fig. 7 Pressure wave at exit point with silencer (First trial) $\left(\mathrm{P}_{\mathrm{rms}}\right)=32.5 \mathrm{~Pa}$ (124.2 dB)

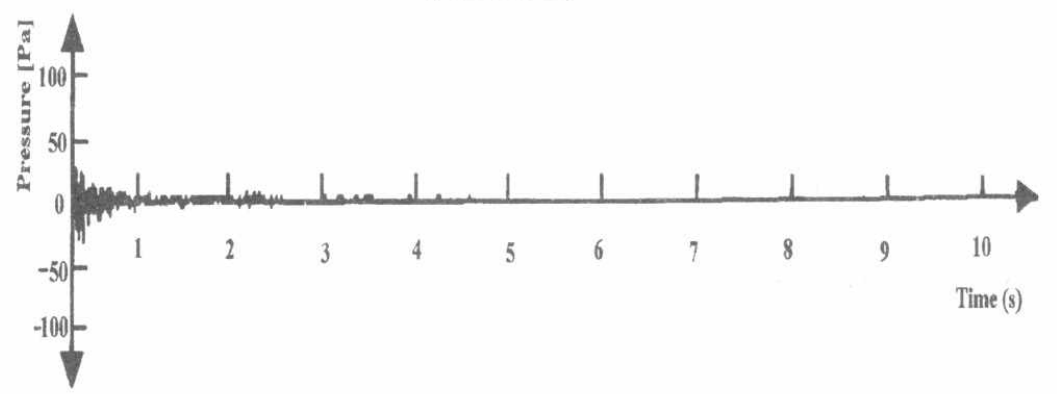

Fig. 8 Pressure wave at exit point without silencer (second trial) $\left(\mathrm{P}_{\mathrm{rms}}\right)=29.25 \mathrm{~Pa}(123.3 \mathrm{~dB})$

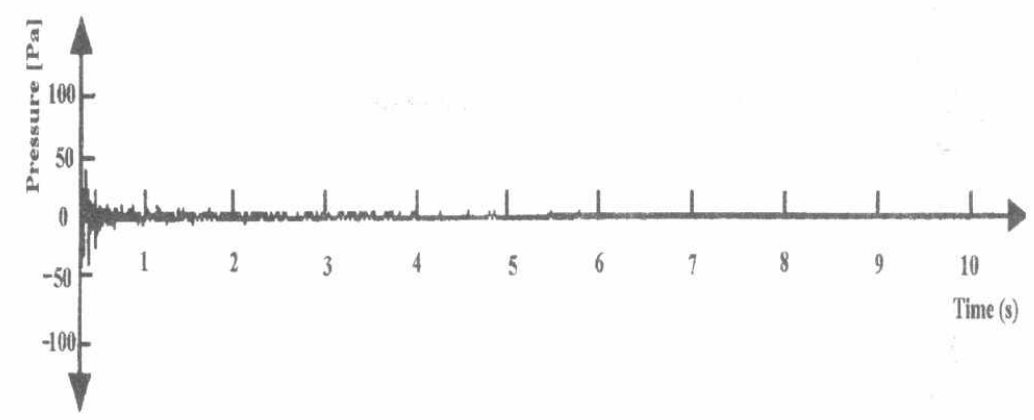

Fig. 9 Pressure wave at exit point with silencer (third trial) $\left(\mathrm{P}_{\mathrm{rms}}\right)=41.5 \mathrm{~Pa}(126.34 \mathrm{~dB})$ 


\section{6 -CONCLUSION :}

Upon analyzing the results of firing tests; it can be concluded that:

1- The proposed silencer works efficiently in supersonic speeds of the flying projectile.

2- Specially in firing weapons; reduction of noise produced by supersonic speed of projectile through reduction of speed to sonic and subsonic is not likely recommended as it is accompanied with high reduction to the kinetic energy of the projectile.

3- The distribution of discharge nozzles in the outer cylinder has a great effect on early suppression of pressure wave, and its increase in a form of back and front perforates causes shortening of the overall silencer length.

4- Although the pressure of gases was reduced and consequently the silencer efficiency reaches $99 \%$, the projectile muzzle energy was reduced by $2.5 \%$ only, then the modified silencer is more efficient.

5- It is recommended to search inside the internal geometry of the silencer and solving the computational fluid dynamic for the flow parameters.

\section{7 - REFERENCES:}

[1] Oswatitch, K., "Intermediate Ballistics," Institute fur theoretishe gasdynamik, Achen, Germany, June 1964.

[2] A. M. Joglekar and M. S. Phadke, "Iterative Modeling of Interior Ballistics of Small Arms", spacecraft J., VOL.19 NO. 7, July 1972, pp. 450-456.

[3] J. I. Erods and P. D. Del Guidice, "Calculation of Muzzle Blast Flowfields," AIAA J, VOl. 13, NO. 8, August 1975, pp. 1048-1055.

[4 ]E. M. Schmidt and D. D. Shear, "Optical Measurement of Muzzle Blast", AIAA J, VOL.13 NO. 8, August 1975, pp. 1086-1091.

[5] Rebicek, V. "Principal problems of Theoretical Interior Ballistics", M. T. C., Cairo, 1976.

[6] Fox, R. W and Mc Donald "Introduction to Fluid Mechanics ", $4^{\text {th }}$ ed. John Willey, New York, 1998.

[7] Blast and Vibration Monitoring, "Nitro Consult" UVS 1608, SN 0044, Sweden, 1996.

[8] Boisson, D \& Cayzac, R. "Study of the Gas Discharge Occurring in a Gun Barrel After the Projectile Departure", $18^{\text {th }}$ International Symposium, San Antonio, TX , U.S.A., 15-19 Nov. 1999.

[9] Gade, S. “ Sound intensity”, B\&K technical review no. 3, Denmark, 1982. 